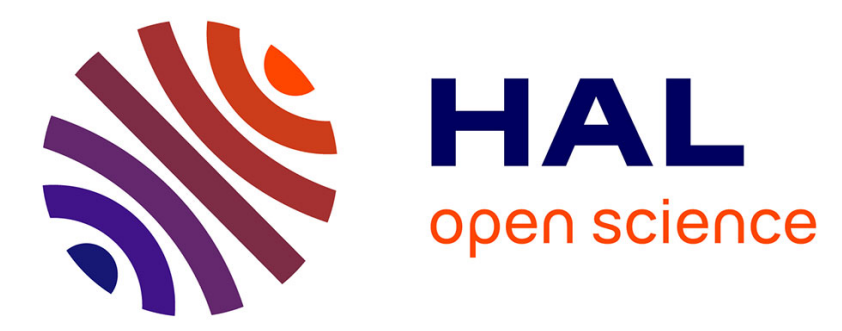

\title{
DFT study of Host-Dopant systems of DPVBi with Organophosphorus $\pi$-Conjugated materials
}

Anusha Valaboju, Krishna Chaitanya Gunturu, Bhanuprakash Kotamarthi, Damien Joly, Muriel Hissler

\section{- To cite this version:}

Anusha Valaboju, Krishna Chaitanya Gunturu, Bhanuprakash Kotamarthi, Damien Joly, Muriel Hissler. DFT study of Host-Dopant systems of DPVBi with Organophosphorus $\pi$-Conjugated materials. Computational and Theoretical Chemistry, 2017, 1113, pp.61-71. 10.1016/j.comptc.2017.05.001 . hal-01520596

\section{HAL Id: hal-01520596 \\ https://hal-univ-rennes1.archives-ouvertes.fr/hal-01520596}

Submitted on 5 Jul 2017

HAL is a multi-disciplinary open access archive for the deposit and dissemination of scientific research documents, whether they are published or not. The documents may come from teaching and research institutions in France or abroad, or from public or private research centers.
L'archive ouverte pluridisciplinaire HAL, est destinée au dépôt et à la diffusion de documents scientifiques de niveau recherche, publiés ou non, émanant des établissements d'enseignement et de recherche français ou étrangers, des laboratoires publics ou privés. 


\section{DFT study of Host-Dopant systems of DPVBi with Organophosphorus m-Conjugated materials}

Anusha Valaboju ${ }^{a}$, Krishna Chaitanya Gunturu ${ }^{b}$, Bhanuprakash Kotamarthi ${ }^{a *}$

anorganic and Physical Chemistry Division and Acsir, CSIR-Indian Institute of Chemical Technology, Hyderabad 500 007, India. *E-mail: bprakash@iict.res.in

${ }^{b}$ School of Chemical Sciences, Swami Ramanand Teerth Marathawada University, Nanded, Maharashtra, India.

and

Damien Jolyc, Muriel Hissler ${ }^{c^{*}}$

'Institut des Sciences Chimiques de Rennes, UMR 6226, CNRS-Université de Rennes 1, Campus de Beaulieu, 35042 Rennes Cedex, France.

*E-mail: muriel.hissler@univ-rennes1.fr

\section{Abstract}

A detailed computational analysis of intermolecular interactions and optoelectronic properties is carried out using DFT/TD-DFT methods for the emissive materials namely bis(2,2'-diphenylvinyl)-1,1'-biphenyl, $\mathbf{D P V B i ,}$ phospholes 2-thienyl 5-fluorenyl thioxophosphole, A and 2-(5-methyl) thienyl 5-fluorenyl thioxophosphole, B and the two host-dopant systems, DPVBi-A(DA) and DPVBi-B(DB). DPVBi is a classical blue emitter and, phosphole-based compounds A and B are the complementary orange emitters for generation of white light emission in Organic Light Emitting Diodes (OLEDs). The intermolecular interactions are analyzed at B2PLYPD/6-31G(d,p) level for homodimers using the data from CSD and heterodimers with possible structures as predicted at B97D/6-31G(d) level of theory. Drift mobilities, based on Marcus theory for both hole and electron transfers are estimated for DPVBi and compounds A and $\mathbf{B}$ in solid state. Vertical and adiabatic excitation energies are calculated for DPVBi and phospholes $\mathbf{A}$ and $\mathbf{B}$ using TD-DFT. To determine the emission energies, excited state geometry optimizations are carried out using B3LYP, CAM-B3LYP, PBE0, M06-2X functionals with $6-31+G(d, p)$ basis set. 
Keywords: White Organic Light Emitting Diodes (WOLEDs), Absorption/Emission, phosphole, Interactions.

\section{Introduction}

Organic Light Emitting Diodes (OLEDs) ${ }^{1}$ are emerging as a fore-front in organic

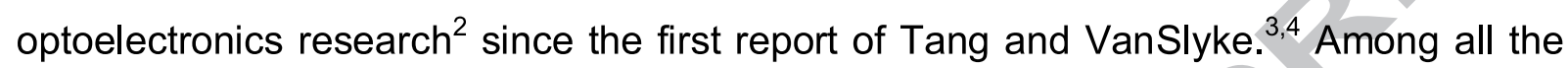
possible applications of organic devices, white organic light-emitting diodes (WOLEDs) $)^{5,6}$ have received considerable interest due to their potential for replacing conventional lighting sources for display backlighting and solid-state lighting. In particular, the WOLEDs have promising properties like improved power efficiency, high color temperature, homogenous large area emission, low operating voltage and simple fabrication process etc. ${ }^{7-11}$ According to Commission Internationale de l'Éclairage (CIE) regulations, white light can be achieved with coordinates close to $(0.313,0.329)$. In this domain, the most general attempt for white light generation is either by adjusting three primary colors i.e. red, green and blue or by mixing two complementary colors through doping. This latter approach is simpler in practice where a blue emitter is doped with an orange emitter. ${ }^{12}$

Phosphole-based functional molecules are of increasing interest in the field of optoelectronics, and have proven to be efficient orange emitters for WOLEDs. ${ }^{13,14}$ Phosphole ${ }^{15,16}$ is weakly aromatic in which the delocalization arises from a hyperconjugation phenomenon involving the exocyclic $P-R \sigma$-bond and the $\pi$-system of the dienic moiety. ${ }^{17-20}$ The variation of the substitution pattern of phospholes and chemical modification of their $\mathrm{P}$ atoms afford thermally stable derivatives having specific optical properties. ${ }^{21-24}$ Amongst phosphole based emitters synthesized by the Réau and Hissler group, ${ }^{13-14}$ thiophene-phosphole-fluorene based orange emitting oligomers (2thienyl 5-fluorenyl thioxophosphole, A; 2-(5-methyl) thienyl 5-fluorenyl thioxophosphole), B (Figure 1)) have been successfully used as dopants of a blue emitting matrix $\left(4,4^{\prime}-\right.$ bis(2,2'-diphenylvinyl)-1,1'-biphenyl (DPVBi) $)^{25}$ for the production of near white-light. $^{12}$ 
In order to address severe drawbacks with respect to the small doping ratios $(0.2-2 \%)$ within the precise controlled rates $( \pm 0.1 \%)$, associated reproducibility of device performance and insensitivity towards the very small concentration changes, the possibility for fine-tuning optical and electrochemical properties of phosphole based conjugated systems for the preparation of WOLEDs has been exploited and used for the development of efficient dopants for DPVBi. ${ }^{12}$ Interestingly, the structurally similar phosphole emitters, A and B, showed very different doping properties. For achieving white emission, the doping rate for $\mathbf{A}$ is very low (0.3\%) when compared to the doping rate of $\mathbf{B}(3.2 \%)$. Moreover, increasing the doping rates for $\mathbf{B}$ from $2.1 \%$ to $3.8 \%$ had only a small effect on the CIE coordinates and also there was no modification of the external quantum efficiency, unlike for compound $\mathbf{A}^{12}$. Hence, phosphole $\mathbf{B}$ has been suggested as an appealing dopant for DPVBi matrix towards the development of easyto-make WOLED. A minor structural change (- $\mathrm{CH}_{3}$ group) between phospholes $\mathbf{A}$ and $\mathbf{B}$ is playing a crucial role in determining the observed doping properties.

An in-depth knowledge of opto-electronic properties at the molecular level is essential for a better understanding of the processes which in turn would help us to improve the design of $\pi$-systems. Density Functional Theory (DFT) has been found to be suitable to study the molecular properties of interest. Time Dependent Density Functional Theory (TD-DFT) ${ }^{26-29}$ is essential to rationalize the optoelectronic properties, and to explore the electronically excited states of the functional molecules. ${ }^{30-33}$ The geometry changes between the fundamental state and the excited states can be determined which are otherwise very challenging to measure experimentally ${ }^{34}$. Liu et al reported a computational analysis of structural, electronic, and optical properties of phosphole-containing $\pi$-conjugated oligomers for LEDs ${ }^{35}$. The authors explained the possible planar excited states of a few phosphole derivatives through the excited state optimizations using CIS calculations. Hu et al reported a DFT study of host-dopant polymer for WOLED comprising a single-polymer system with simultaneous blue (polyfluorene as a blue host) and orange (2,1,3-benzothiadiazole-based derivative as an orange dopant) emissions. ${ }^{36}$ In addition to the 2,5-disubstituted systems, the effect of the extension of the $\pi$-system on the physical properties of planar phosphorus- 
containing polycyclic aromatic hydrocarbons has been unveiled through frontier molecular orbitals and nucleus independent chemical shift values. ${ }^{37-38}$

In this work, through our calculations at molecular level, we study the structural and optoelectronic properties of orange emitting thiophene-phosphole-fluorene oligomers, phospholes $\mathbf{A}$ and $\mathbf{B}$, and the well known blue emitter, DPVBi. We address the difference in behaviour of dopants $\mathbf{A}$ and $\mathbf{B}$ based on DFT calculations of the respective homodimeric systems.

\section{Computational Methods}

Geometry optimizations are carried out using Gaussian 09 software. ${ }^{39}$ Crystal structures of DPVBi, Phospholes $\mathbf{A}$ and $\mathbf{B}$ are retrieved from Cambridge Structural Database (CSD). ${ }^{40}$ The ground state $\left(G S, S_{0}\right.$ ) neutral geometries are optimized at $B 3 L Y P^{41-43} / 6-31+G(d, p)$ level of theory. Vibrational frequencies are calculated to ensure that these $S_{0}$ geometries correspond to real minima on the potential energy surface. At this geometry, aiming at realizing an efficient TD-DFT protocol within the vertical approximation, the lowest singlet excited states are computed using hybrid exchange correlation functionals $\mathrm{B} 3 \mathrm{LYP}, \mathrm{PBE} \mathrm{O}^{44}, \mathrm{M} 06-2 \mathrm{X}^{45}$ and range separated hybrid functionals, CAM-B3LYP ${ }^{46}, \quad L C-\omega P B E^{47-49}, L C-B L Y P^{50}$ in dichloromethane (DCM) solvent. The solvent effects ((DCM) are included using the IEFPCM formalism. ${ }^{51}$ The software Gausssum is used to interpret the nature of transitions. ${ }^{52}$ First singlet excited state $\left(E S, S_{1}\right)$ geometry optimizations (adiabatic TD-DFT) are carried out using B3LYP, CAM-B3LYP, PBE0 and M06-2X functionals with $6-31+g(d, p)$ basis set. Symmetry constraints were turned off to avoid any complications in following the electronic state of interest. In addition to this, an ultrafine grid for numerical integrations is used for a better description of the excited states. Emission energies are obtained at both Linear Response (LR) and State-Specific (SS) formalisms. ${ }^{53,54}$ Radiative lifetimes $(\tau)$ are calculated using the Einstein transition probabilities according to the equation ((1), all in atomic units). ${ }^{55}$ 


$$
\tau=\frac{c^{3}}{2 E_{F l u}^{2} f}
$$

Where $c$ is the velocity of light, $E_{F l u}$ is the excitation energy, and $f$ is the oscillator strength.

Using the optimized $\mathrm{S}_{0}$ geometries, the internal reorganization energies based on Marcus theory are calculated at B3LYP/6-31+G(d,p) level of theory (Figure $S 3, \mathrm{SI}$ ). Frequency calculations were carried out for optimized cations and anion geometries to ensure that these stationary points are minima on the potential energy surface.

Intermolecular interaction energies are obtained using dispersion corrected B2PLYPD ${ }^{56,57} / 6-31 G(d, p)$ for homodimers of DPVBi, phospholes $\mathbf{A}$ and $\mathbf{B}$, using CSD data and heterodimers DA and DB with optimized geometries at $B 97 D^{58} / 6-31 G(d)$ level of theory. Counterpoise corrected basis set superposition errors ${ }^{59,60}$ have been calculated and added to the interaction energies. These calculations are based on the following equations,

$$
\begin{aligned}
& \Delta E_{\text {int }}(A B)=E_{A B}^{A B}(A B)-E_{A}^{A}(A B)-E_{B}^{B}(A B) \\
& \Delta E_{\text {int }}^{c p}(A B)=\left[E_{A B}^{A B}(A B)-E_{A}^{A}(A B)-E_{B}^{B}(A B)\right]+\left[E_{A B}^{A}(A)-E_{A B}^{A B}(A)+E_{A B}^{B}(B)-E_{A B}^{A B}(B)\right] \\
& =\Delta E_{\text {int }}(A B)+\delta \mathrm{E}_{A B}^{\mathrm{BSSE}}
\end{aligned}
$$

Where $\mathrm{A}$ and $\mathrm{B}$ are interacting molecules, and the notation $E_{Y}^{Z}(X)$ represents the energy of system $X$ at geometry $Y$ with basis set $Z$.

Hole and electron drift mobilities are calculated for homodimers based on the hopping model where the charge hops between two neighboring molecules ( $i$ and $j)^{61-63}$. The effective charge transfer integrals are calculated for heterodimers using B3LYP functional and a valence triple zeta basis set with two polarization functions (TZ2P basis) within the Amsterdam Density Functional (ADF) Code. ${ }^{64-66}$ The holetransfer/electron-transfer reactions between the neighboring molecules is shown as

$$
A^{+/-}+A \rightarrow A+A^{+/-}
$$


Where $A$ is the neutral molecule interacting with neighboring oxidized $\left(A^{+}\right)$or reduced $\left(A^{-}\right)$molecule. According to Einstein relation, the drift mobility of hopping $\mu,{ }^{61}$ can be expressed as

$$
\mu=\frac{e}{K_{b} T} D
$$

Where $e$ is the electronic charge, $D$ is the isotropic charge diffusion coefficient, $k_{b}$ is the Boltzmann constant, and $\mathrm{T}$ is the temperature.

According to Marcus theory, ${ }^{62}$ the rate constant for charge transfer (CT)/hopping rate is defined as

$$
k_{i}=\frac{4 \pi^{2}\left(J_{e f f}\right)_{i j}^{2}}{\mathrm{~h}} \frac{1}{\sqrt{\left(4 \pi \lambda k_{b} T\right)}} \mathrm{e}^{\left(-\lambda / 4 k_{b} T\right)}
$$

Where $\left(U_{e f f}\right)_{i j}$ is the effective charge transfer (hole/electron) transfer integral/coupling matrix element between neighboring molecules, $\lambda$ is the reorganization energy $\left(\lambda_{+}\right.$for

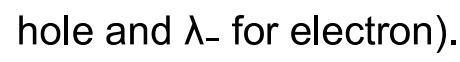

The effective charge-transfer integrals $\left(U_{e f f}\right)_{i j}$ (equation (7)) for hole and electron transfer are estimated using the Entire Dimer Hamiltonian (EDH) method, as suggested by Siebbles and co-workers and implemented in ADF software for most of the possible dimer interaction pathways. The matrix elements of the molecular Kohn-Sham Hamiltonian on the basis of fragment orbitals are used to calculate site energies $e_{i}$ and $e_{j}$, charge transfer integrals $\left(J_{i j}\right)$ and the overlap integrals, $S_{i j}$.

$$
\left(U_{e f f}\right)_{i j}=\frac{J_{i j}-S_{i j}\left(e_{i}+e_{j}\right) / 2}{1-S_{i j}^{2}}
$$

\section{Results and Discussion}

\section{Geometries at Ground states and Excited States}


Comparison of ground state (GS) geometries has been carried out for all the molecules with the experimental data and their respective excited state (ES) geometries. The selected bond lengths and dihedral angles along with the labeling schemes of the optimized neutral GS and the lowest singlet ES geometries obtained at $B 3 L Y P / 6-31+G(d, p)$ level of theory of all the molecules, in dichloromethane solvent are collected in Table S1.

DPVBi In the GS, the bond lengths agree well with the crystal structure ${ }^{67}$, very small changes are observed. The inter-ring distance of biphenyl moiety, bond 1 , is elongated by $0.002 \AA$. The intra-ring $\mathrm{C}-\mathrm{C}$ bonds of the biphenyl moiety, bonds 2 to 7 , are elongated by $\approx 0.02 \AA$. The connecting vinyl' C-C bonds 8 to 11 are elongated not more than $\approx 0.01 \AA$. The dihedral angle between biphenyl moiety $\left(\Phi_{1}\right)$ is twisted by $\approx 34^{\circ}$, when compared to the experimental value of almost $0^{\circ}$, which indicates non-planarity in the GS geometry, whereas the dihedral angles at terminal vinyl groups are very less deviated from experiment. This deviation in dihedral angles of biphenyl between calculated and experimental values in solid state has been attributed to the intermolecular forces. ${ }^{68}$ In the ES, there is a slight decrease in bond lengths $1,4,5,8$ and 10, 11 and a slight elongation in bond lengths 2, 3, 6, 7 and 9. There is a decrease in the torsional angle $\Phi_{1}$ of about $30^{\circ}$, making the geometry near-planar in ES from twisted GS w.r.t the biphenyl moiety. The terminal vinyl groups are twisted in ES $\left(\Phi_{2}\right.$ and $\Phi_{3}$ are $19.5^{\circ}$ and $-19.6^{\circ}$ respectively). Accordingly, the dipole moment from GS (0.21 Debye) to the ES (0.04 Debye) is decreased. The schematic representation of observed changes in geometry of DPVBi and phospholes A and B from non-planarity to planarity is shown in Figure 2.

Phospholes $\boldsymbol{A}$ and $\boldsymbol{B} \quad$ The cyclohexane ring, in both the phosphole dopants $\mathbf{A}$ and $B$, is almost planar in the crystal but a chair form is considered for optimizations. In the optimized GS, all the bond measures agree well with those measured in the crystal structure. Bond lengths around the phosphorus atom and the bond $\mathrm{C}_{3}-\mathrm{C}_{4}$ show very slight elongations in both compounds $\mathbf{A}$ and $\mathbf{B}$. The twist angles between the central phosphole and the side thiophene or the fluorenyl ring are observed as $17.1^{\circ}\left(-5.4^{\circ}\right)$ and $53.6^{\circ}\left(64.1^{\circ}\right)$ respectively in $\mathbf{A}(\mathbf{B})$ in GS. This result indicates that conjugation between 
phosphole and thiophene is more effective than that with fluorenyl ring. From GS to ES, $\mathrm{P}-\mathrm{C}_{2}$ and $\mathrm{P}-\mathrm{C}_{5}$ bond lengths are contracted by $0.02 \AA$ and the inter-ring bonds $\mathrm{C}_{2}-\mathrm{C}_{7}$ and $\mathrm{C}_{5}-\mathrm{C}_{6}$ by about $0.03 \AA$ and $0.04 \AA$ respectively. In addition, larger structural reorganization is seen in case of $C_{2}-C_{3}, C_{3}-C_{4}$ and $C_{4}-C_{5}$ bonds. Furthermore significant changes in dihedral angles between central phosphole ring and the side thiophene or the fluorenyl moieties is seen in ES of $\mathbf{A}$ and $\mathbf{B}$ compared to their GS. They are observed at $-5.4^{\circ}\left(-11.2^{\circ}\right)$ and $20.4^{\circ}\left(27.9^{\circ}\right)$ respectively in $\mathbf{A}$ (B). Thus, these observations facilitate higher order conjugation in ES of $\mathbf{A}$ and $\mathbf{B}$ than their respective GS geometries.

\section{Frontier molecular orbitals}

It is important to examine the frontier molecular orbitals to ascertain the optical transitions and the charge transfer properties. The frontier molecular orbital plots with their corresponding energies obtained at $B 3 L Y P / 6-31+g(d, p)$ level of theory in gas phase are given in Figure 3a. In DPVBi, both the HOMO and LUMO are spread over the entire molecule. In phospholes $\mathbf{A}$ and $\mathbf{B}$, in accordance with the geometrical parameters, HOMOs are mainly distributed over the phosphole, thiophene moieties with small coefficients on fluorenyl moiety, whereas LUMOs are confined majorly on phosphole and thiophene moieties.

In the charge hopping regime, it is essential to examine the frontier orbitals of interacting molecules. The frontier molecular orbitals of homodimers of DPVBi, $\mathbf{A}$ and $\mathbf{B}$ calculated at $B 3 L Y P / 6-31+G(d, p)$ level of theory in gas phase are given in Figure $S 1$ and those of heterodimers DPVBi-A (DA), DPVBi-B (DB) calculated at B3LYP/6$31+G(d, p) / / B 97 D / 6-31 G(d)$ level of theory in gas phase are shown in Figure S2, SI. The extent of splitting of HOMO (LUMO) and HOMO-1 (LUMO+1) is proportional to hole (electron) mobility between the dimers. Symmetric crystal packing and absence of $\pi-\pi$ interactions between dimers of DPVBi results the near degeneracy of frontier molecular orbitals. A few dimers of dopants experience a few $\pi-\pi$ interactions along with $\mathrm{CH}-\pi$ stabilizing interactions, which lead to non-degeneracy of HOMO (LUMO) and HOMO-1 
(LUMO+1) orbitals (vide supra). Larger HOMO (LUMO) and HOMO-1 (LUMO+1) splitting is seen for homodimer AA4 of A by $0.36 \mathrm{eV}(0.41 \mathrm{eV})$, whereas less orbital energy splitting is seen in case of $\mathbf{B}$, i.e. $0.20 \mathrm{eV}$ and $0.13 \mathrm{eV}$ respectively for HOMO and HOMO-1, and LUMO and LUMO+1 for its homodimers BB3 and BB1.

\section{Ionization Potential and Electron Affinity}

The calculated ionization potentials (IP), electron affinities (EA), reorganization energies, HOMO \& LUMO energies and HOMO-LUMO gap (HLG) at B3LYP/6$31+G(d, p)$ level of theory in gas phase are listed in Table 1. The calculated HOMO and LUMO energies of DPVBi are $5.47 \mathrm{eV}$ and $1.92 \mathrm{eV}$ respectively. In comparison, HOMO and LUMO levels of $\mathrm{A}$ are located at $5.49 \mathrm{eV}$ and $2.30 \mathrm{eV}$ respectively with reduced HLG of $3.19 \mathrm{eV}$. In general, the HLG of donor should be higher than the HLG of acceptor for a feasible energy transfer when doped ${ }^{69}$. The methyl group, which differentiates the phospholes $\mathbf{A}$ and $\mathbf{B}$, has an impact on frontier molecular orbital levels with the presence of node mainly in HOMO between methyl group and thiophene moiety. This leads to the larger destabilization of HOMO of B obtained at $5.44 \mathrm{eV}$ and small effect on LUMO obtained at $2.19 \mathrm{eV}$ with negligible change in HLG. This report was further confirmed with experimental results of large oxidation potential of $\mathbf{B}$ compared to $\mathbf{A}$ while reduction potentials are almost same ${ }^{12}$. In case of energy of ionization, less IP and large EA values are usually expected for better hole and electron mobilities respectively. Interestingly, the IP values of DPVBi, $\mathbf{A}$ and $\mathbf{B}$ are not much different whereas EA values are significantly different. Adiabatic EA of $\mathbf{A}$ and $\mathbf{B}$ are large $-1.41 \mathrm{eV}$ and $-1.33 \mathrm{eV}$ respectively compared with $-1.06 \mathrm{eV}$ of DPVBi. Hence, acceleration of electron mobility is expected with the presence of $\mathbf{A}$ and $\mathbf{B}$ when doped with blue emitter, DPVBi.

\section{Reorganization energies}


The estimated internal reorganization energies (Scheme to calculate reorganization energy in Figure $S 3, S I)$ at $B 3 L Y P / 6-31+G(d, p)$ level of theory are included in Table 1 and the corresponding optimized geometries of cation and anion are sorted in supporting information (Table S2).

The reorganization energies of the hole and electron transfer are $0.310 \mathrm{eV}$ and $0.425 \mathrm{eV}$ respectively in DPVBi. Slightly larger reorganization energies are obtained for phospholes, $\lambda_{+}$is $0.441 \mathrm{eV}, \lambda_{-}$is $0.506 \mathrm{eV}$ in $\mathrm{A}$ and $\lambda_{+}$is $0.480 \mathrm{eV}$ and $\lambda_{-}$is $0.576 \mathrm{eV}$ in $\mathbf{B}$, which is due to the rigidity of the distorted tetrahedral phosphole moiety in the structure of dopants. The observed $\lambda_{+}$are smaller than $\lambda_{-}$, indicating that the hole transfer rate is higher than the electron transfer rate in these molecules.

In DPVBi, shortening and elongation of bond lengths along the long axis is observed upon oxidation and reduction. Particularly, the bonds, 1, 8 and symmetrically identical bonds are shortened by about $0.03 \AA$ while inter-ring bond pairs 2,3 and 6,7 are elongated by about $0.014-0.02 \AA$. The changes in the geometrical parameters indicate the better conjugation between rings in oxidized and reduced states than in neutral state. This is further supported by the torsion angle within the biphenyl unit $158^{\circ}$ and $162^{\circ}$ respectively for oxidation and reduced states (Table S2.a, SI). Though, the torsion angles at the terminal phenyl rings are more twisted than in neutral state. In dopants $\mathbf{A}$ and $\mathbf{B}$, major changes in geometry are observed for the bonds at the central phosphole ring after ionization when compared to respective neutral geometries (Table S2.b, SI). More profound elongations observed, upon reduction, for $\mathrm{P}=\mathrm{S}, \mathrm{P}-\mathrm{C}_{1}$ bonds by $0.04 \AA$ and $0.02 \AA$ respectively for both $\mathbf{A}$ and $B$ while they are shortened upon oxidation by $0.01 \AA$ and $0.01 \AA$ respectively. In contrast, $\mathrm{P}-\mathrm{C}_{2}$ and $\mathrm{P}-\mathrm{C}_{5}$ bonds are shortened and elongated by about $0.03 \AA$ and $0.01 \AA$ respectively during reduction and oxidation steps. $\mathrm{C}_{3}-\mathrm{C}_{2}$ and $\mathrm{C}_{4}-\mathrm{C}_{5}$ are elongated during oxidation and reduction. At the same time, the inter-ring bonds, $\mathrm{C}_{2}-\mathrm{C}_{7}$ and $\mathrm{C}_{5}-\mathrm{C}_{6}$ are shortened by the same order while oxidation indicates the increased charge mobility between phosphole ring and fluorenyl/thiophene rings. 


\section{Interactions and Drift mobilities}

In charge transport regime, intermolecular interactions are very important. ${ }^{70-71}$ Keeping this in view, Interactions at dimer level are analyzed at B2PLYPD/6-31G(d,p) for homodimers (DD, AA and BB) and at B2PLYPD/6-31G(d,p)//B97D/6-31G(d) level for heterodimers (DA and DB). All possible immediate neighbors of monomers in the crystal packing have been considered. The interaction energies $\left(\Delta \mathrm{E}_{\text {int }}^{c p}\right.$ in $\left.\mathrm{kcal} / \mathrm{mol}\right)$ effective charge transfer integrals $\left(\left(\mathrm{J}_{\text {eff }}\right)_{\mathrm{ij}}\right.$ in $\left.\mathrm{eV}\right)$, rate constants (in $\left.\mathrm{S}^{-1}\right)$, and drift mobilities ( $\mu$ in $\mathrm{cm}^{2} / \mathrm{s}$ ) for hole and electron transfer of DPVBi and the dopants $\mathbf{A}$ and B are summarized in Table 2. The transfer integral values for hole and electron transport are discussed as absolute values herewith. Crystal structure of DPVBi shows a near planarity at the biphenyl part along with vinyl bridge and the terminal phenyl rings are non-planar. This reflects in the herringbone crystal packing where $\pi-\pi$ interactions are few, and instead $\mathrm{CH}-\pi$ interactions stabilize the crystal packing, which leads to smaller interaction energies. The highest $\Delta \mathrm{E}_{\text {int }}^{c p}(-10.73 \mathrm{kcal} / \mathrm{mol})$ is seen for parallel stacked homodimer DD2 with $9.277 \AA$ centroid-centroid distance, larger electron transfer integral $(10.20 \mathrm{meV})$ and corresponding rate constant is $4.39 \times 10^{10} \mathrm{~S}^{-1}$. Furthermore, the slipped stacking of two monomers, with a larger centroid-centroid distance $17.319 \AA$ resulted in the transfer integral of $2.46 \mathrm{meV}$ for electron transport. It is worth to be noted that, irrespective of the orientation and interaction energies $\left(\Delta \mathrm{E}_{\mathrm{int}}^{c p}\right)$, larger electron transfer integrals have been obtained when compared to hole transfer integrals for DPVBi. However, the calculated drift mobilities for hole $\left(\mu_{+}\right)$and electron $\left(\mu_{-}\right.$ ) transport are $1.37 \times 10^{-3}$ and $1.94 \times 10^{-3} \mathrm{~cm}^{2} / \mathrm{Vs}$.

Similar to DPVBi, $\mathrm{CH}-\pi$ interactions stabilize the crystal packing majorly for both A and B. Homodimer AA2 shows the largest $\Delta \mathrm{E}_{\text {int }}^{c p}$ of $-12.9 \mathrm{kcal} / \mathrm{mol}$ and largest $\mathrm{J}_{+}$ 27.30 meV which has $\mathrm{CH}-\pi$ interactions between cyclohexane ring and the fluorenyl moiety of the neighboring molecule, and between the benzene ring of one phosphole of and the cyclohexane ring of the other monomer. A $\pi-\pi$ interaction is seen in homodimer AA5 separated by $3.883 \AA$ between fluorenyl and phenyl rings along with $\mathrm{CH}-\mathrm{m}$ interaction with $2.618 \AA$ between fluorenyl rings of two monomers. Thus dimer AA5 has $\Delta \mathrm{E}_{\text {int }}^{c p}$ of $-7.08 \mathrm{kcal} / \mathrm{mol}$ and large $\mathrm{J}_{+}$of $17.30 \mathrm{meV}$. Furthermore, notable 
effective transfer integrals have been found for electron (10.30 meV) in homodimer AA3 for which $\mathrm{CH}-\pi$ interactions are seen with thiophene ring but small $\Delta \mathrm{E}_{\text {int }}^{c p}$ has been obtained. Apart from this, dimer AA1 with a centroid-centroid distance of $8.248 \AA$ shows effective transfer integral for both electron and hole: $3.10 \mathrm{meV}$ and $1.90 \mathrm{meV}$ respectively which results in smaller hole and electron charge drift mobilities i.e., 1.15 $\mathrm{x} 10^{-2}$ and $1.21 \times 10^{-3} \mathrm{~cm}^{2} \mathrm{~N}$ s respectively.

Interestingly, the crystal packing of B presents several dimers with $\pi-\pi$ interactions which are not observed for $\mathbf{A}$. This behavior can be attributed to the difference in crystal packing due to the added methyl group in B. Here, the $\pi-\pi$ interactions are seen between thiophene and phosphole rings of two monomers. Even though, the centroid-centroid distance is larger (11.753 $\AA)$ in dimer BB3, the near planarity of thiophene and phosphole rings allow effective interaction between $\pi$ clouds of two monomers. Also in case of dimer BB1, more number of $\mathrm{CH}-\pi$ interactions have been seen for thiophene and phosphole-phenyl rings which leads to larger $\Delta \mathrm{E}_{\text {int }}^{c p}(-17.12$ $\mathrm{kcal} / \mathrm{mol}$ ) amongst all dimers. Similarly, in case of dimer BB4, the effective overlapping is seen between fluorenyl rings of two monomers, though large centroid-centroid distance of $10.561 \AA$ is seen. Hence larger effective transfer integrals have been obtained for dimer BB3 and dimer BB1 as $91.6 \mathrm{meV}$ and $56.20 \mathrm{meV}$ respectively for hole and electron transport which are larger than for any dimer of $\mathbf{A}$ (Table 3 ). This is reflected in large charge drift mobilities as $1.59 \times 10^{-1} \mathrm{~cm}^{2} / \mathrm{s}$ and $1.14 \times 10^{-2} \mathrm{~cm}^{2} / \mathrm{V}$ respectively for hole and electron transfer.

Intermolecular interactions between DPVBi and dopants $\mathbf{A}$ and $\mathbf{B}$ have been studied by considering most of the possible orientations between them. The estimated interaction energies, effective charge transfer integrals are given in Table S3 respectively at B2PLYPD/6-31G(d,p) level using optimized geometries at B97D/6$31 \mathrm{G}(\mathrm{d})$ level of theory. Most stable heterodimers of DA and DB are included in Figure $3 b$. The interaction energies and the electron/hole transfer integrals are almost similar in the heterodimers. 


\section{Absorption and Emission spectra}

Table 4 collects the TD-DFT/LR-PCM based low lying vertical excitation energies in B3LYP, M06-2X, PBE0, CAM-B3LYP, LC-BLYP and LC-wPBE functionals and 6$31+g(d, p)$ basis set, in dichloromethane solvent media using ground state optimized geometries obtained at $B 3 L Y P / 6-31+G(d, p)$ level of theory in gas phase. The transition energies $\left(\Delta \mathrm{E}^{\mathrm{abs}}\right.$ in $\left.\mathrm{eV}\right)$ with oscillator strengths and main configurations for the first three singlet excited states of all the molecules are reported. The range-separated hybrid functional LC-BLYP and LC-WPBE show poorer performance as when compared with experimental $S_{0} \rightarrow S_{1}$ transition energies by $0.4 \mathrm{eV}$ to $0.5 \mathrm{eV}$ for three molecules. The popular hybrid functional B3LYP and PBE0 show much deviation of about $0.45 \mathrm{eV}$ and $0.33 \mathrm{eV}$ respectively for DPVBi molecule. At the same time, transition energies obtained of dopants A and B are moderately good with these functionals. Apart from this, coulomb attenuating CAM-B3LYP and meta-hybrid M06-2X functionals provide better agreement with the experimental excitation energies. The calculations are showing about $0.04-0.16 \mathrm{eV}$ deviation with the experimental values $3.54 \mathrm{eV}, 3.00 \mathrm{eV}$ and 2.95 $\mathrm{eV}$ respectively for DPVBi, $\mathbf{A}$ and $\mathbf{B}$. The $S_{0} \rightarrow S_{1}$ transitions are $\pi-\pi^{*}$ localized on the entire molecule in the case of DPVBi and in the case of $\mathbf{A}$ and $\mathbf{B}$ dopants, they are mainly confined in the phosphole and thiophene rings (vide supra). The character of $S_{0} \rightarrow S_{2}$ and $S_{0} \rightarrow S_{3}$ transitions in DPVBi are not different from the prominent $S_{0} \rightarrow S_{1}$ transition. At the same time, the dopants are showing different character in $S_{0} \rightarrow S_{2}$ and $\mathrm{S}_{0} \rightarrow \mathrm{S}_{3}$ transitions. It is seen from Figure $\mathrm{S} 4$ and Figure S5 (using natural transition orbitals) that these transitions in the solvent are confined within the middle part of the molecular structure i.e. sulphur and phosphole ring.

The fluorescence emission energies of all the molecules have been obtained by using LR-PCM and SS-PCM formalisms in dichloromethane solvent media, and are compared with experimental data in Table 5. First singlet excited-state $\left(\mathrm{S}_{1}\right)$ geometry optimizations were performed employing various exchange correlation functionals like B3LYP, PBE0, M06-2X and CAM-B3LYP with 6-31+g(d,p) basis set.

In B3LYP, CAM-B3LYP, PBE0, and M06-2X functionals, emission energies $\left(\Delta \mathrm{E}^{\mathrm{em}}\right)$ for DPVBi are obtained as $2.14 \mathrm{eV}, 2.25 \mathrm{eV}, 2.22 \mathrm{eV}$ and $2.27 \mathrm{eV}$ respectively 
when LR-PCM formalism is used. The emissions are significantly improved to $2.35 \mathrm{eV}$, $2.45 \mathrm{eV}, 2.43 \mathrm{eV}$ and $2.46 \mathrm{eV}$ respectively in SS-PCM method. Similarly, the emissions for $\mathbf{A}$ and $\mathbf{B}$ are improved by about $0.10 \mathrm{eV}$ with SS-PCM method than with LR-PCM. This can be explained as the alteration of geometry and electronic density from ground state to excited state (vide supra). It leads to the reorientation of solvent molecules in respective excited state of DPVBi, $\mathbf{A}$ and $\mathbf{B}$ molecules. This behavior is accounted in SS-PCM formalism and hence possesses superior performance for predicting fluorescence emission than LR-PCM. To infer the emissions in all molecules, M06-2X and CAM-B3LYP functionals with SS-PCM formalism showed better match with the experimental values than the other functionals, though there is an overestimation of about $0.33 \mathrm{eV}-0.45 \mathrm{eV}$ for all three molecules.

Using the calculated fluorescence energies $\left(\Delta \mathrm{E}^{\mathrm{em}}\right)$ and corresponding oscillator strengths from LR-PCM approximation, the radiative lifetimes $(\tau, \mathrm{ns})$ have been calculated and included in Table 5 . It is seen that irrespective of DFT methodology, phospholes exhibit longer radiative lifetimes than those of DPVBi. The blue emitter has shorter lifetime of 3.6 ns compared to 12 ns and 16.6 ns for dopants $\mathbf{A}$ and $\mathbf{B}$ respectively in M06-2X.

\section{Conclusions}

In this study, we have carried out a detailed computational analysis of the significant molecular interactions of DPVBi, the blue emitter, phospholes $\mathbf{A}$ and $\mathbf{B}$, the orange dopants. The geometries for ground state, excited state, oxidized state and reduced state of the three molecules have been optimized and compared with the experimental data. The geometry of ES is found to be more planar than in GS of blue emitter and dopants considered in this study. In case of phosphole dopants, upon oxidation and reduction, greater conjugation is seen between phosphole ring and thiophene and fluorenyl rings while phenyl ring attached to phosphole ring is not in molecular plane due to distorted tetrahedral character of $P$ atom. Similarly, biphenyl and vinyl bridge attain near planarity upon ionization in DPVBi. 
The inspection of frontier orbitals revealed that the splitting of frontier orbitals is prominent in dopants while near degeneracy is seen in DPVBi. This behavior is more significant in case of heterodimers, DA and DB than their respective homodimers, which indicates the larger interactions between the molecules in heterodimers. The corresponding reorganization energies, interaction energies, effective transfer integrals, rate constants and drift mobilities of hole and electron transfer have been calculated and analyzed. $\pi-\pi$ interactions dominate in phosphole B solid state. Thiophenethiophene and fluorenyl-fluorenyl interactions in this case are stronger due to parallel stacking. This may also be present in the heterodimer DB, thereby showing a different behaviour from DA.

This work looks toward the development of host-dopant systems comprising the active organic blue emitters and phosphole based orange emitters to achieve better white organic light emitting diodes.

\section{Associated Content}

\section{Corresponding Authors}

*E-mail: bprakash@iict.res.in, muriel.hissler@univ-rennes1.fr

Notes

The authors declare no competing financial interest.

\section{Supporting information}

GS and ES geometries of DPVBi, A and B; Frontier molecular orbitals(FMOs) of homodimers of DPVBi, A and B, heterodimers DA and DB; scheme to calculate reorganization energy; bond parameters of cation and anion optimized geometries of DPVBi, A and B; Interaction energies, Effective charge transfer integrals, Rate constants, and Drift mobilities for hole and electron transfer of heterodimers DA and DB; FMOs and Natural transition orbitals of DPVBi, A and B.

\section{Acknowledgements}


KBP and AV thank the Director, IICT, for the constant encouragement in this work. Grant under NWP-055 from CSIR is gratefully acknowledged. This work is supported by the Ministère de la Recherche et de l'Enseignement Supérieur, the Institut Universitaire de France, the CNRS, the Région Bretagne and Indo-French "Joint Laboratory for Sustainable Chemistry at the Interfaces".

\section{References}

1. D. J. Gaspar and E. Polikarpov, OLED fundamentals: materials, devices, and processing of organic light-emitting diodes, CRC Press, 2015.

2. S.A. Van Slyke, C. Chen, C.W. Tang, Organic electroluminescent devices with improved stability, Appl. Phys. Lett. 69 (1996) 2160-2162.

3. C.W. Tang, S.A. Van Slyke, Organic electroluminescent diodes, Appl. Phys. Lett. 51 (1987) 913-915.

4. S.A. Van Slyke, C. Chen, C.W. Tang, Organic electroluminescent devices with improved stability, Appl. Phys. Lett. 69 (1996) 2160-2162.

5. M.C. Gather, A. Köhnen, K. Meerholz, White organic light-emitting diodes, Adv. Mater. 23 (2011) 233-248.

6. B.W. D'Andrade, S.R. Forrest, White organic light-emitting devices for solid-state lighting, Adv. Mater. 16 (2004) 1585-1595.

7. S. Reineke, M. Thomschke, B. Lüssem, K. Leo, White organic light-emitting diodes: Status and perspective, Rev. Mod. Phys. 85 (2013) 1245.

8. H. Sasabe, J. Kido, Development of high performance OLEDs for general lighting, J. Mater. Chem. C. 1 (2013) 1699-1707.

9. Z. Wu, D. Ma, Recent advances in white organic light-emitting diodes, Mater. Sci. Eng. R-Rep. 107 (2016) 1-42.

10.J. Kido, K. Hongawa, K. Okuyama, K. Nagai, White light-emitting organic electroluminescent devices using the poly ( $N$-vinylcarbazole) emitter layer doped with three fluorescent dyes, Appl. Phys. Lett. 64 (1994) 815-817.

11.J. Kido, M. Kimura, K. Nagai, Multilayer white light-emitting organic electroluminescent device, Science. 267 (1995) 1332. 
12.D. Joly, D. Tondelier, V. Deborde, W. Delaunay, A. Thomas, K. Bhanuprakash, B. Geffroy, M. Hissler, R. Réau, White Organic Light-Emitting Diodes Based on Quench-Resistant Fluorescent Organophosphorus Dopants, Adv. Funct. Mater. 22 (2012) 567-576.

13. M.P. Duffy, W. Delaunay, P.-A. Bouit, M. Hissler, m-Conjugated phospholes and their incorporation into devices: components with a great deal of potential, Chem. Soc. Rev. 45 (2016) 5296-5310.

14.D. Joly, P.-A. Bouit, M. Hissler, Organophosphorus derivatives for electronic devices, J. Mater. Chem. C. 4 (2016) 3686-3698.

15.T. Baumgartner, R. Réau, Organophosphorus $\pi$-conjugated materials, Chem. Rev. 106 (2006) 4681-4727.

16.M.G. Hobbs, T. Baumgartner, Recent Developments in Phosphole-Containing Oligo-and Polythiophene Materials, Eur. J. Inorg. Chem. 2007 (2007) 36113628.

17.L. Nyulászi, Aromaticity of phosphorus heterocycles, Chem. Rev. 101 (2001) 1229-1246.

18. E. Mattmann, F. Mathey, A. Sevin, G. Frison, De-aromatizing phosphole, J. Org. Chem. 67 (2002) 1208-1213.

19. A. Hughes, C. Srivanavit, The chemistry of phosphole derivatives, J. Heterocyclic Chem. 7 (1970) 1-24.

20. F. Mathey, Phosphorus-carbon heterocyclic chemistry: the rise of a new domain, Elsevier Health Sciences2001.

21. C. Fave, T.-Y. Cho, M. Hissler, C.-W. Chen, T.-Y. Luh, C.-C. Wu, R. Réau, First examples of organophosphorus-containing materials for light-emitting diodes, J. Am. Chem. Soc. 125 (2003) 9254-9255.

22. M.P. Duffy, P.-A. Bouit, B. Geffroy, D. Tondelier, M. Hissler, Phosphorus-based chromophores: Emitters for OLEDs, Phosphorus, Sulfur, and Silicon. 190 (2015) 845-853.

23. O. Fadhel, M. Gras, N. Lemaitre, V. Deborde, M. Hissler, B. Geffroy, R. Réau, Tunable Organophosphorus Dopants for Bright White Organic Light-Emitting Diodes with Simple Structures, Adv. Mater. 21 (2009) 1261-1265. 
24.Y. Matano, Phospholes and Related Compounds, Organic Redox Systems: Synthesis, Properties, and Applications, (2015) 477-501.

25. K. Ono, T. Hiei, K. Saito, Synthesis and luminescent properties of bis (fluoren-9ylidenemethyl) aromatics: Green and red materials in organic electroluminescent devices, Heterocycles. 68 (2006) 667-672.

26.E. Runge, E.K.U. Gross, Density-Functional Theory for Time-Dependent Systems, Phys. Rev. Lett. 52 (1984) 997-1000.

27.M.E. Casida, Response theory for molecules, Recent Advances in Density Functional Methods:(Part I), 1 (1995) 155.

28. R.E. Stratmann, G.E. Scuseria, M.J. Frisch, An efficient implementation of timedependent density-functional theory for the calculation of excitation energies of large molecules, J. Chem. Phys. 109 (1998) 8218-8224.

29. M.A. Marques, N.T. Maitra, F.M. Nogueira, E.K. Gross, A. Rubio, Fundamentals of time-dependent density functional theory, Springer Science \& Business Media2012.

30.C. Adamo, D. Jacquemin, The calculations of excited-state properties with TimeDependent Density Functional Theory, Chem. Soc. Rev. 42 (2013) 845-856.

31.C.A. Guido, D. Jacquemin, C. Adamo, B. Mennucci, On the TD-DFT accuracy in determining single and double bonds in excited-state structures of organic molecules, J. Phys. Chem. A. 114 (2010) 13402-13410.

32.A.D. Laurent, D. Jacquemin, TD-DFT benchmarks: A review, Int. J. Quantum Chem. 113 (2013) 2019-2039.

33.F. Santoro, D. Jacquemin, Going beyond the vertical approximation with time-dependent density functional theory, Wiley Interdiscip Rev Comput Mol Sci. 6 (2016) 460-486.

34.S. Chidirala, H. Ulla, A. Valaboju, M.R. Kiran, M.E. Mohanty, M. Satyanarayan, G. Umesh, K. Bhanuprakash, V.J. Rao, Pyrene-Oxadiazoles for Organic LightEmitting Diodes: Triplet to Singlet Energy Transfer and Role of HoleInjection/Hole-Blocking Materials, J. Org. Chem. 81 (2015) 603-614. 
35. Y.L. Liu, J.K. Feng, A.M. Ren, Structural, electronic, and optical properties of phosphole-containing $\pi$-conjugated oligomers for light-emitting diodes, J. Comput. Chem. 28 (2007) 2500-2509.

36. B. Hu, J. Zhang, Y. Chen, Theoretical investigation on the white-light emission from a single-polymer system with simultaneous blue and orange emission (Part II), Eur. Polym. J. 47 (2011) 208-224.

37.F. Riobé, R. Szűcs, P.A. Bouit, D. Tondelier, B. Geffroy, F. Aparicio, J. Buendía, L. Sánchez, R. Réau, L. Nyulászi, Synthesis, Electronic Properties and WOLED Devices of Planar Phosphorus-Containing Polycyclic Aromatic Hydrocarbons, Chem. Eur. J. 21 (2015) 6547-6556.

38. Y. Matano, A. Saito, T. Fukushima, Y. Tokudome, F. Suzuki, D. Sakamaki, H. Kaji, A. Ito, K. Tanaka, H. Imahori, Fusion of Phosphole and 1, 1'-Biacenaphthene: Phosphorus (V)-Containing Extended $\pi$-Systems with High Electron Affinity and Electron Mobility, Angew. Chem. Int. Ed. 50 (2011) 80168020.

39. M. J. Frisch, G. W. Trucks, H. B. Schlegel, G. E. Scuseria, M. A. Robb, J. R. Cheeseman, G. Scalmani, V. Barone, B. Mennucci and G. A. Petersson, et al., Gaussian 09 Revision B.01, Gaussian Inc., Wallingford, CT, 2009

40.C.R. Groom, I.J. Bruno, M.P. Lightfoot, S.C. Ward, The Cambridge structural database, Acta Cryst. (2016). B72, 171-179.

41.A.D. Becke, Density-functional thermochemistry. III. The role of exact exchange, J. Chem. Phys., 98 (1993) 5648-5652.

42. A.D. Becke, Density-functional thermochemistry. IV. A new dynamical correlation functional and implications for exact-exchange mixing, J. Chem. Phys. 104 (1996) 1040-1046.

43. C. Lee, W. Yang, R.G. Parr, Development of the Colle-Salvetti correlation-energy formula into a functional of the electron density, Phys. Rev. B. 37 (1988) 785.

44.C. Adamo, V. Barone, Toward reliable density functional methods without adjustable parameters: The PBE0 model, J. Chem. Phys. 110 (1999) 6158-6170.

45.Y. Zhao, D.G. Truhlar, The M06 suite of density functionals for main group thermochemistry, thermochemical kinetics, noncovalent interactions, excited 
states, and transition elements: two new functionals and systematic testing of four M06-class functionals and 12 other functionals, Theor. Chem. Acc. 120 (2008) 215-241.

46.T. Yanai, D.P. Tew, N.C. Handy, A new hybrid exchange-correlation functional using the Coulomb-attenuating method (CAM-B3LYP), Chem. Phys. Lett. 393 (2004) 51-57.

47. O.A. Vydrov, G.E. Scuseria, Assessment of a long-range corrected hybrid functional, J. Chem. Phys. 125 (2006) 234109.

48. O.A. Vydrov, J. Heyd, A.V. Krukau, G.E. Scuseria, Importance of short-range versus long-range Hartree-Fock exchange for the performance of hybrid density functionals, J. Chem. Phys. 125 (2006) 074106.

49. O.A. Vydrov, G.E. Scuseria, J.P. Perdew, Tests of functionals for systems with fractional electron number, J. Chem. Phys. 126 (2007) 154109.

50. H. likura, T. Tsuneda, T. Yanai, K. Hirao, A long-range correction scheme for generalized-gradient-approximation exchange functionals, J. Chem. Phys. 115 (2001) 3540-3544.

51.J. Tomasi, B. Mennucci, and R. Cammi, Quantum mechanical continuum solvation models, Chem. Rev. 105 (2005) 2999-3093.

52. N. M. O'Boyle, A. L. Tenderholt. K. M. Langner. J. Comp. Chem. 29(2008) 839845.

53.R. Improta, V. Barone, G. Scalmani, M.J. Frisch, A state-specific polarizable continuum model time dependent density functional theory method for excited state calculations in solution, J. Chem. Phys. 125 (2006) 054103.

54. R. Improta, G. Scalmani, M.J. Frisch, V. Barone, Toward effective and reliable fluorescence energies in solution by a new state specific polarizable continuum model time dependent density functional theory approach, The J. Chem. Phys. 127 (2007) 074504.

55. I. Litani-Barzilai, V. Bulatov, V.V. Gridin, I. Schechter, Detector based on timeresolved ion-induced voltage in laser multiphoton ionization and laser-induced fluorescence, Anal. Chim. Acta. 501 (2004) 151-156. 
56. T. Schwabe, S. Grimme, Double-hybrid density functionals with long-range dispersion corrections: higher accuracy and extended applicability, Phys. Chem. Chem. Phys. 9 (2007) 3397-3406.

57.S. Grimme, Semiempirical GGA-type density functional constructed with a longrange dispersion correction, J. Comput. Chem. 27 (2006) 1787-1799.

58.S. Grimme, Do special noncovalent $\Pi-\Pi$ stacking interactions really exist?, Angew. Chem. Int. Ed. 47 (2008) 3430-3434.

59.S.F. Boys, F.d. Bernardi, The calculation of small molecular interactions by the differences of separate total energies. Some procedures with reduced errors, Mol. Phys. 19 (1970) 553-566.

60.S. Simon, M. Duran, J. Dannenberg, How does basis set superposition error change the potential surfaces for hydrogen-bonded dimers?, J. Chem. Phys. 105 (1996) 11024-11031.

61.S.-H. Wen, A. Li, J. Song, W.-Q. Deng, K.-L. Han, W.A. Goddard, First-Principles Investigation of Anistropic Hole Mobilities in Organic Semiconductors, J. Phys. Chem. B. 113 (2009) 8813-8819.

62.R.A. Marcus, On the theory of oxidation-reduction reactions involving electron transfer. I, J. Chem. Phys. 24 (1956) 966-978.

63. N. Hush, Adiabatic Rate Processes at Electrodes. I. Energy-Charge Relationships, J. Chem. Phys. 28 (1958) 962-972.

64.G.t. Te Velde, F.M. Bickelhaupt, E.J. Baerends, C. Fonseca Guerra, S.J. van Gisbergen, J.G. Snijders, T. Ziegler, Chemistry with ADF, J. Comput. Chem. 22 (2001) 931-967.

65. C.F. Guerra, J. Snijders, G. Te Velde, E. Baerends, Towards an order-N DFT method, Theor. Chem. Acc. 99 (1998) 391-403.

66.ADF, SCM, Theoretical Chemistry, Vrije Universiteit, Amsterdam, The Netherlands, 2016.

67.H.-N. Liu, G. Zhang, L. Hu, P.-F. Su, Y.-F. Li, 4, 4'-Bis (2, 2-diphenylvinyl)-1, 1'biphenyl, Acta Cryst. E67 (2011) 0220.

68. A.t. Hargreaves, S.H. Rizvi, The crystal and molecular structure of biphenyl, Acta Cryst. 15 (1962) 365-373. 
69.F. Laquai, Y.S. Park, J.J. Kim, T. Basché, Excitation energy transfer in organic materials: from fundamentals to optoelectronic devices, Macromol. Rapid Commun. 30 (2009) 1203-1231.

70.V. Coropceanu, J. Cornil, D.A. da Silva Filho, Y. Olivier, R. Silbey, J.-L. Brédas, Charge transport in organic semiconductors, Chem. Rev. 107 (2007) 926-952.

71.S.E. Koh, C. Risko, D.A. da Silva Filho, O. Kwon, A. Facchetti, J.L. Brédas, T.J. Marks, M.A. Ratner, Modeling Electron and Hole Transport in Fluoroarene-Oligothiopene Semiconductors: Investigation of Geometric and Electronic Structure Properties, Adv. Funct. Mater. 18 (2008) 332-340. 
Figure 1. Sketch map of the structures DPVBi, Phospholes A and B studied in this work.

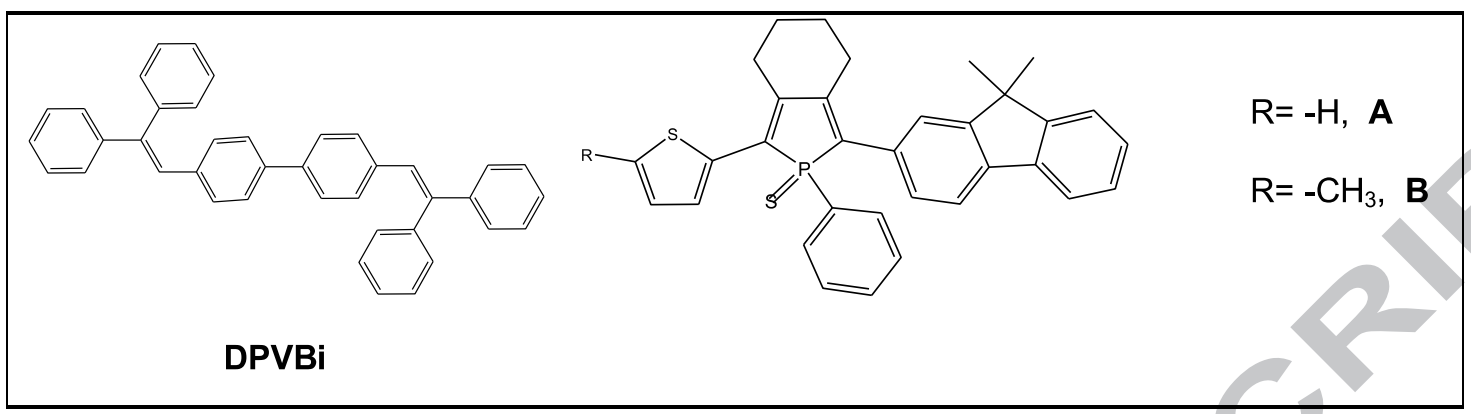

Figure 2. Comparison of DFT ground state (GS) and TDDFT excited state (ES) geometries at B3LYP/6-31+g(d,p) level of theory in dichloromethane solvent: Side views of DPVBi and phospholes $\mathbf{A}$ and $\mathbf{B}$.

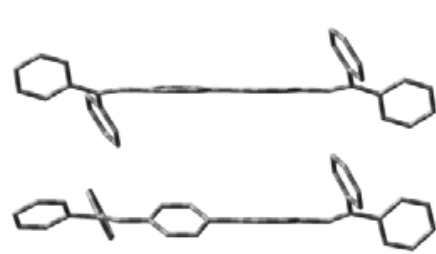

DPVBi
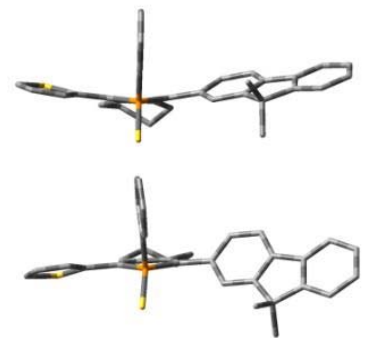

A

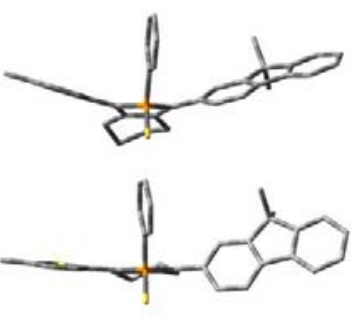

ES

GS

B 
Figure 3a. Frontier molecular Orbitals (Energies in eV) of DPVBi, Phospholes A and B calculated at B3LYP/6-31+G(d,p) level of theory in gas phase (isovalue $=0.02$ ).

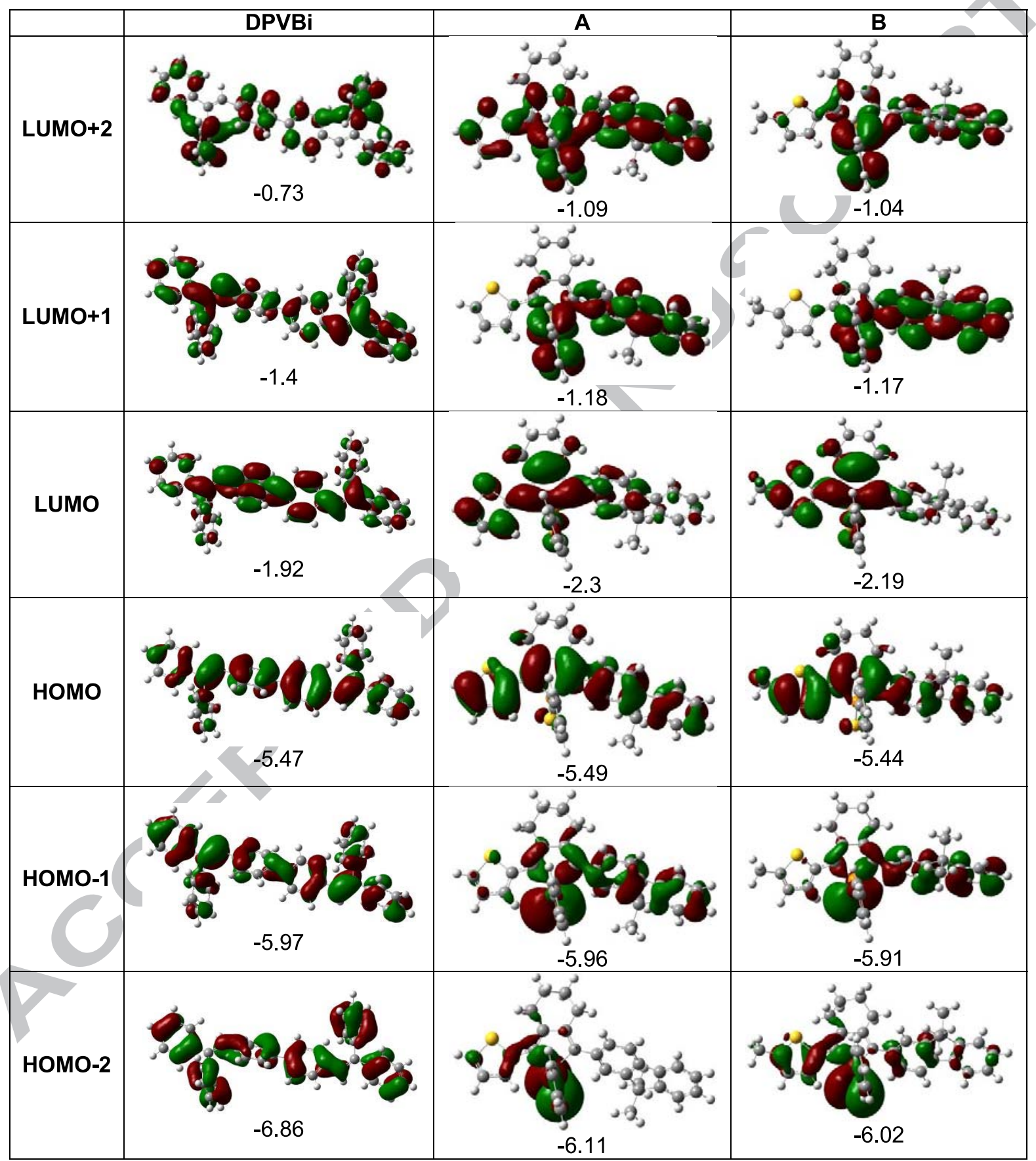


Figure 3b. Frontier molecular Orbitals (Energies in eV) of most stable homodimers DD2, AA2, BB1 calculated at B3LYP/6-31+G(d,p) level and heterodimers DA19, DB12 at B3LYP/6-31+G(d,p)//B97D/6-31G(d) level of theory in gas phase (isovalue=0.02).

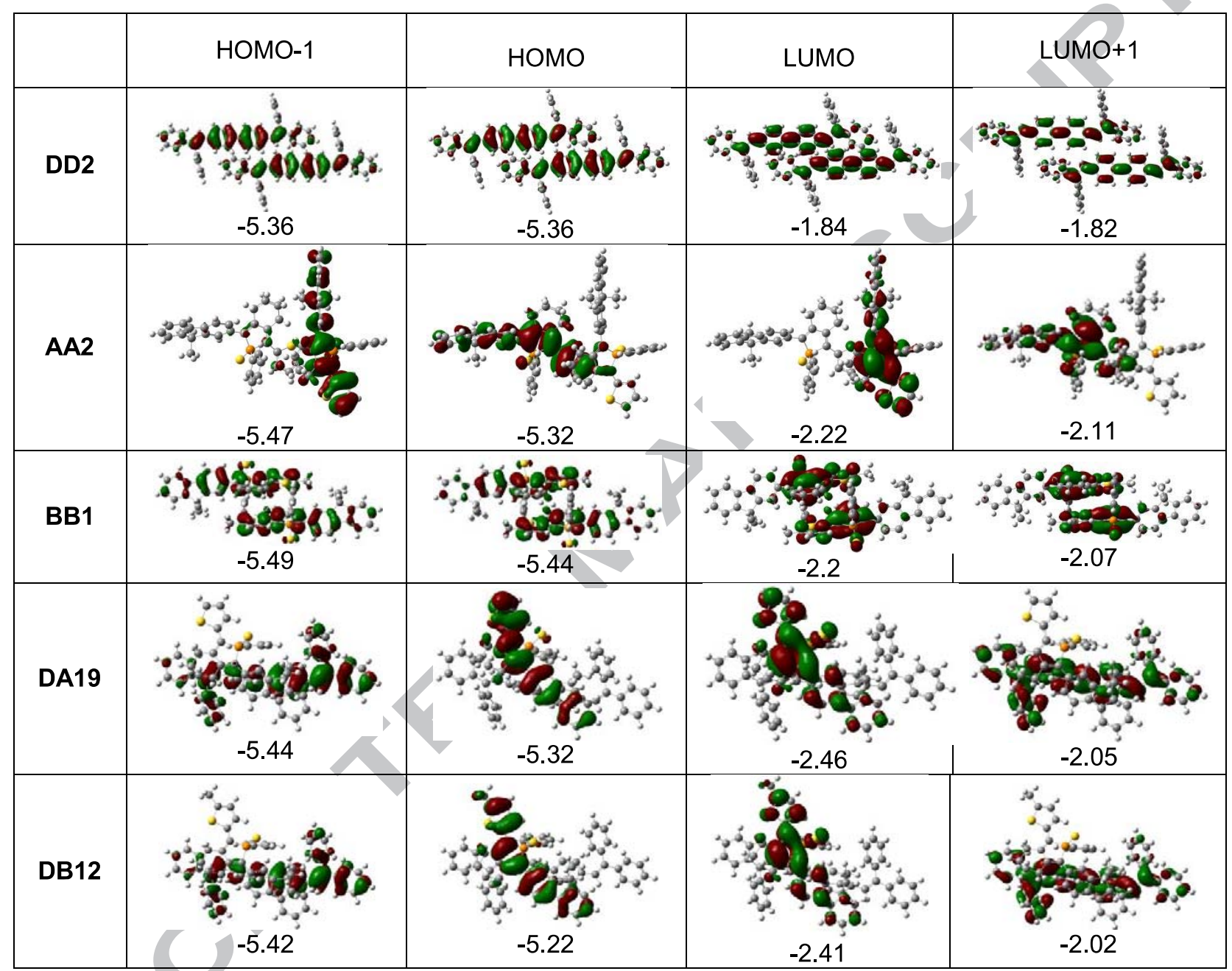


Table 1. Ionization potentials (Vertical (VIP) and Adiabatic (AIP)), Electron affinities (Vertical (VEA) and Adiabatic (AEA)), Reorganization energies for hole and electron transport $(\lambda)$, HOMO, LUMO energies and HOMO-LUMO gaps (HLG) of DPVBi and Phospholes A, B (all in eV), calculated at B3LYP/6-31+G(d,p) level of theory in gas phase.

\begin{tabular}{|c|c|c|c|c|c|c|c|c|c|}
\hline & VIP & AIP & VEA & AEA & $\lambda_{+}$ & $\lambda$. & номо & LUMO & HLG \\
\hline DPVBi & 6.49 & 6.33 & -0.93 & -1.15 & 0.310 & 0.425 & -5.47 & -1.92 & 3.55 \\
\hline A & 6.62 & 6.39 & -1.15 & -1.41 & 0.441 & 0.506 & -5.49 & -2.30 & 3.19 \\
\hline B & 6.57 & 6.32 & -1.03 & -1.33 & 0.480 & 0.576 & 511 & -2.19 & 3.25 \\
\hline
\end{tabular}

Table 2. The calculated Interaction energies $\left(\Delta \mathrm{E}_{\text {int }}^{\mathrm{cp}}\right.$ in $\left.\mathrm{kcal} / \mathrm{mol}\right)$ at $B 2 P L Y P D / 6-31 \mathrm{G}(\mathrm{d}, \mathrm{p})$ level of theory, Effective charge transfer integrals $\left(\left(\mathrm{J}_{\text {eff }}\right)_{\mathrm{ij}}\right.$ in eV) at B3LYP/TZ2P level of theory, Rate constants (in $\mathrm{S}^{-1}$ ), and Drift mobilities for hole and electron transfer $(\mu$ in $\mathrm{cm}^{2} / \mathrm{Vs}$ ) of homodimers of DPVBi, phospholes $\mathbf{A}$ and $\mathbf{B}$. (Reorganization energy obtained from B3LYP/6-31+G(d,p) level is used to calculate charge mobilities).

\begin{tabular}{|c|c|}
\hline DP & $\mu=1.94 \times 10^{-3}$ \\
\hline $\begin{array}{l}\text { center-center: } 8.990 \AA \\
\mathrm{CH} \text { - } \mathrm{I}: 3.984,3.368,3.499,3.333 \AA \\
\begin{array}{l}\mathrm{E} \text { int }=-10.42, \delta \mathrm{E}_{A B}^{\mathrm{BSSE}}=2.90, \Delta \mathrm{E}_{\mathrm{int}}^{\mathrm{CP}}=-7.52 \\
\mathrm{~J}_{+}=2.30 \times 10^{-04}, \mathrm{~J}=3.91 \times 10^{-03} \\
\mathrm{~K}_{+}=7.96 \times 10^{07}, \mathrm{~K}=6.47 \times 10^{09}\end{array}\end{array}$ & $\begin{array}{l}\text { center-center: } 9.277 \\
2 \text { sets of equal interactions } \\
\mathrm{CH} \text { - } \mathrm{x} \text { : } 3.840,3.603,3.940,3.202,3.845 \AA \\
\Delta \mathrm{E}_{\text {int }}=-16.12, \delta \mathrm{E}_{A B}^{\mathrm{BSE}}=5.38, \Delta \mathrm{E}_{\mathrm{int}}^{\mathrm{CP}}=-10.73 \\
\mathrm{~J}_{+}=1.50 \times 10^{-04}, \mathrm{~J}=-1.02 \times 10^{-02}, \\
\mathrm{~K}_{+}=3.39 \times 10^{07}, \mathrm{~K}=4.39 \times 10^{10}\end{array}$ \\
\hline
\end{tabular}




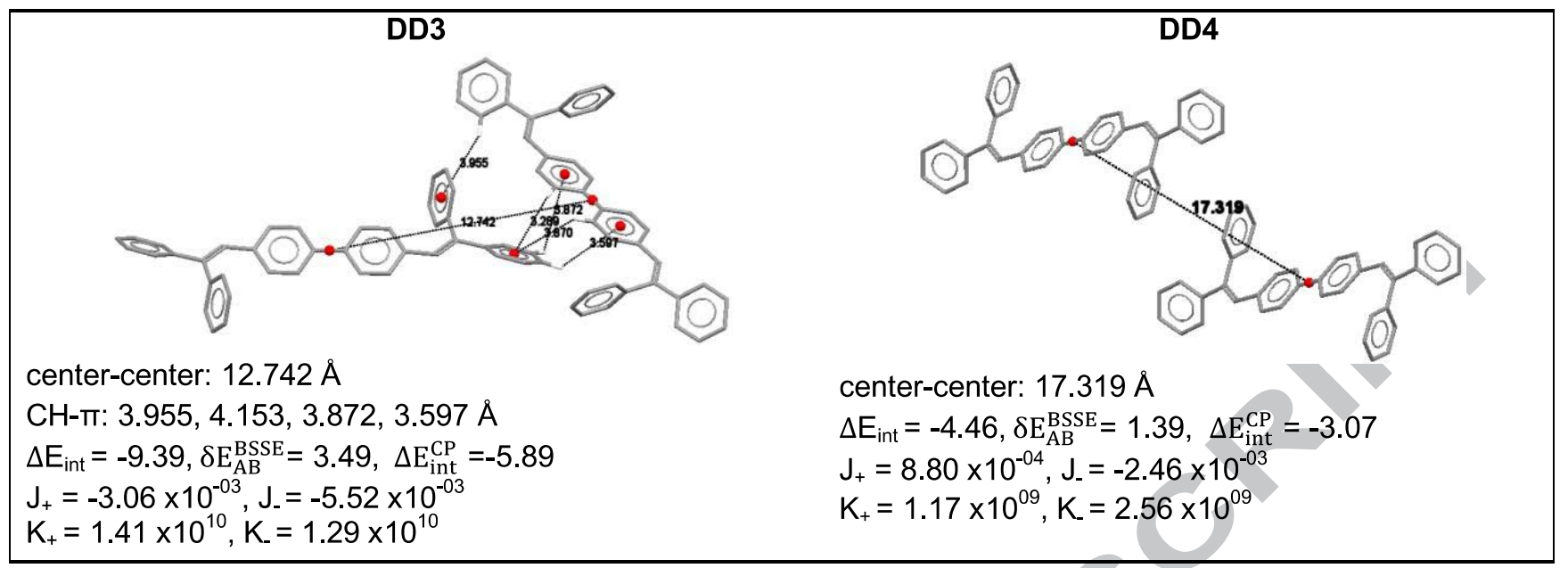

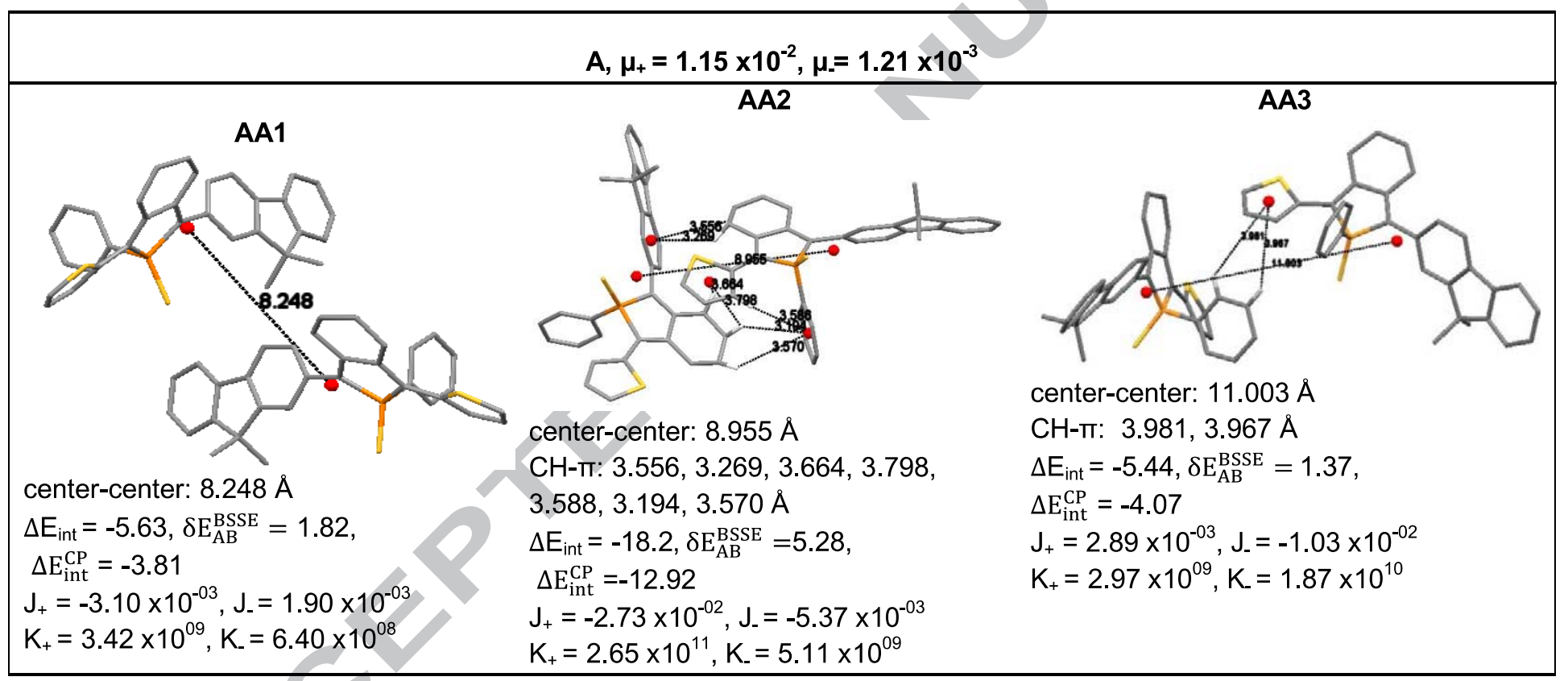




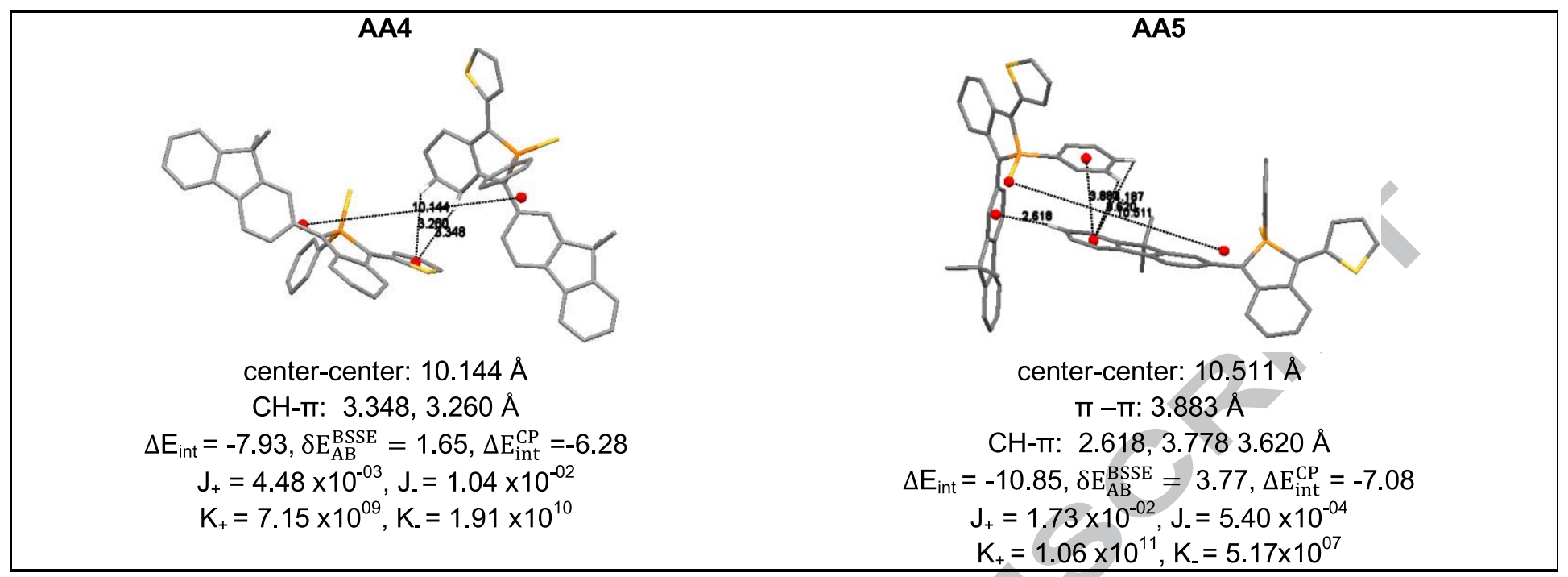

\begin{tabular}{|c|c|}
\hline & $\times 10^{-2}$ \\
\hline $\begin{array}{l}\text { center-center: } 8.603 \AA, 2 \text { sets of equal inte } \\
\mathrm{CH} \text {-п: } 3.410,3.431 \AA \\
\Delta \mathrm{E}_{\text {int }}=-23.06, \delta \mathrm{E}_{\mathrm{AB}}^{\mathrm{BSS}}=5.94, \Delta \mathrm{E}_{\mathrm{int}}^{\mathrm{CP}}=-17.12 \\
\mathrm{~J}_{+}=2.15 \times 10^{-02}, \mathrm{~J}=-5.62 \times 10^{-02} \\
\mathrm{~K}_{+}=1.08 \times 10^{11}, \mathrm{~K}=2.67 \times 10^{11}\end{array}$ & $\begin{array}{l}\text { center-center: } 9.069 \AA, \mathrm{CH}-\pi: 3.636,2.821 \AA \\
\Delta \mathrm{E}_{\text {int }}=-7.29, \delta \mathrm{E}_{\mathrm{AB}}^{\mathrm{BSSE}}=2.09, \Delta \mathrm{E}_{\mathrm{int}}^{\mathrm{CP}}=-5.20 \\
\mathrm{~J}_{+}=2.32 \times 10^{-03}, \mathrm{~J}=8.40 \times 10^{04} \\
\mathrm{~K}_{+}=1.26 \times 10^{09}, \mathrm{~K}=5.96 \times 10^{07}\end{array}$ \\
\hline
\end{tabular}




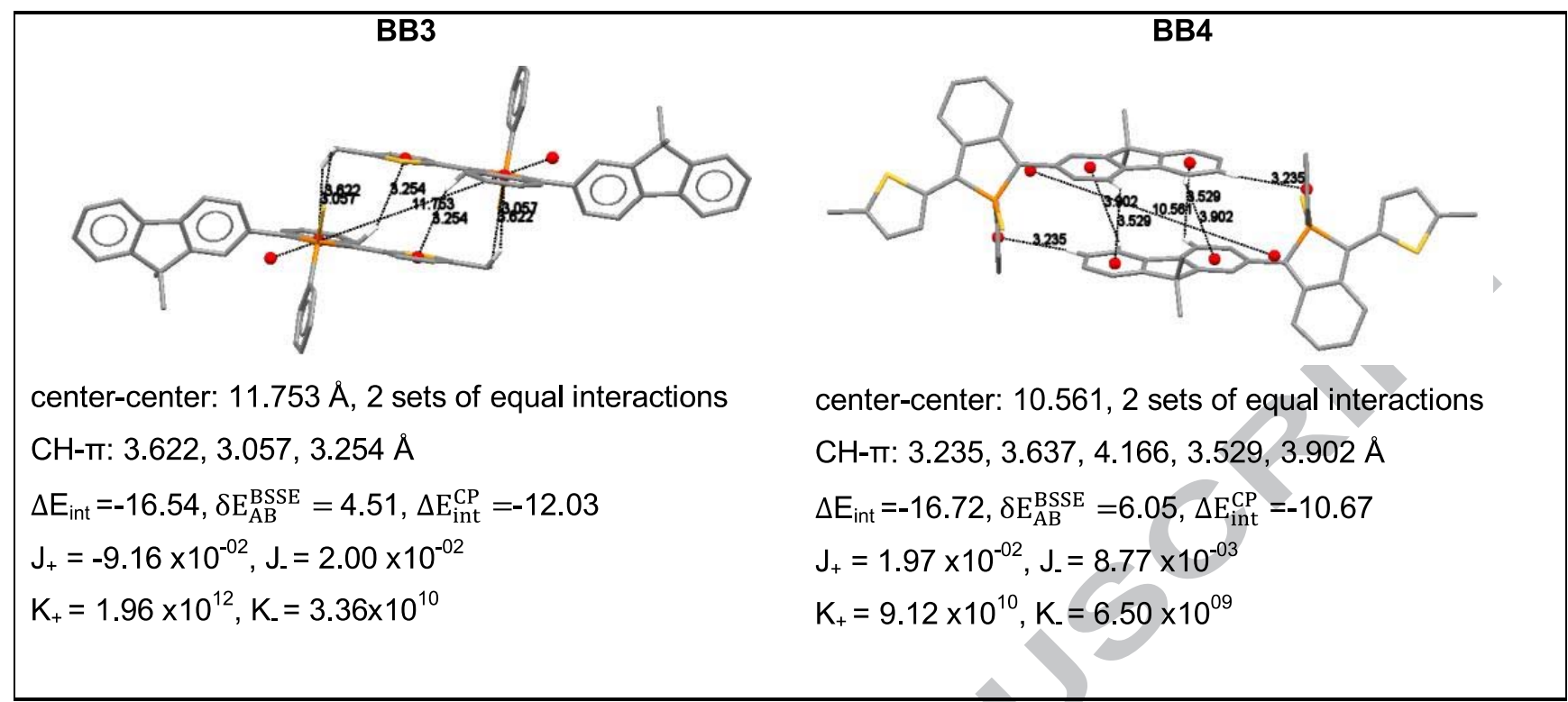

Table 3. Comparison of effective charge transfer integrals $\left(\left(\mathrm{J}_{\mathrm{eff}}\right)_{\mathrm{ij}}\right.$ in $\left.\mathrm{eV}\right)$ for hole and electron transfer of homodimers of phospholes A and B at B3LYP/TZ2P level of theory.
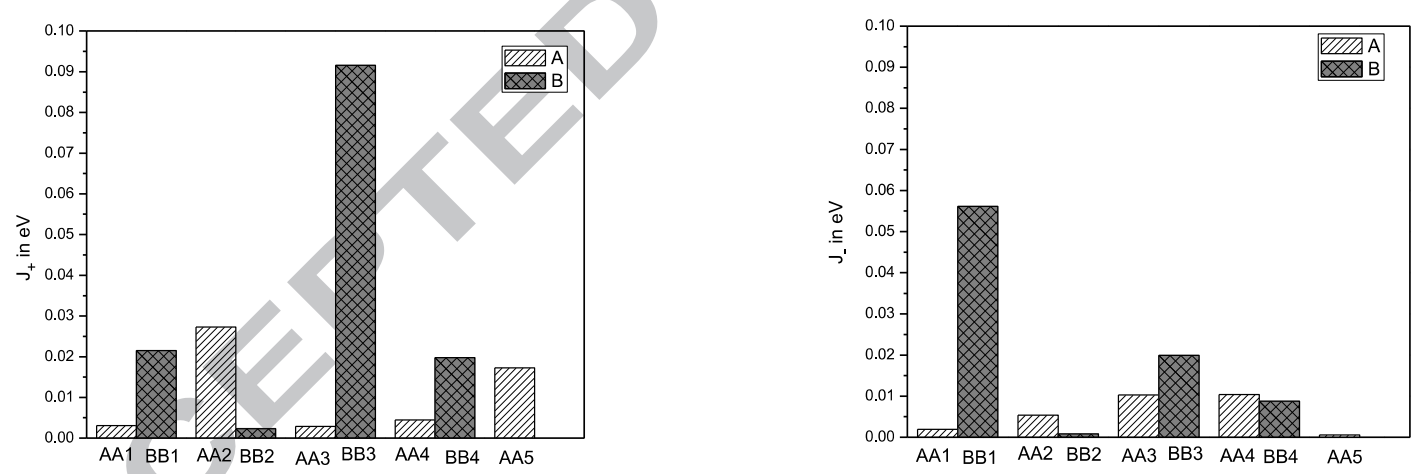
Table 4. Calculated singlet vertical excitation energies $\left(\Delta \mathrm{E}^{\mathrm{abs}}, \mathrm{S}_{0} \rightarrow \mathrm{S}_{\mathrm{n}}\right.$ ) (in eV) with Oscillator strength $f$, of DPVBi, phospholes A and B computed with the IEF-PCM-TD$\mathrm{X} / 6-31+g(d, p) / / B 3 L Y P / 6-31+G(d, p)$ approach (X denotes different functionals in dichloromethane solvent).

\begin{tabular}{|c|c|c|c|c|c|c|c|c|c|c|}
\hline \multirow{3}{*}{$\begin{array}{l}\text { Functional } \\
\qquad(\mathrm{X})\end{array}$} & \multirow{3}{*}{ State } & \multicolumn{3}{|c|}{ DPVBi } & \multicolumn{3}{|c|}{$\mathbf{A}$} & \\
\hline & & $\Delta \mathrm{E}^{\mathrm{abs}}$ & $f$ & Major & $\Delta \mathrm{E}^{\mathrm{abs}}$ & $f$ & Major & $\Delta \mathrm{E}^{\mathrm{abs}}$ & & Major \\
\hline & & & & Contribution & & & Contribution & & & Contribution \\
\hline \multirow[t]{6}{*}{ B3LYP } & S1 & 3.09 & 1.7457 & $\mathrm{H} \rightarrow \mathrm{L}(98 \%)$ & 2.72 & 0.5991 & $\mathrm{H} \rightarrow \mathrm{L}(98 \%)$ & 2.76 & 0.5097 & $\mathrm{H} \rightarrow \mathrm{L}(98 \%)$ \\
\hline & S2 & 3.66 & 0.0027 & $\mathrm{H}-1 \rightarrow \mathrm{L}(92 \%)$ & 3.16 & 0.0335 & $\mathrm{H}-2 \rightarrow \mathrm{L}(38 \%)$ & 3.19 & 0.0247 & $\mathrm{H}-2 \rightarrow \mathrm{L}(42 \%)$ \\
\hline & & & & & & & $\mathrm{H}-1 \rightarrow \mathrm{L}(60 \%)$ & & & $\mathrm{H}-1 \rightarrow \mathrm{L}(55 \%)$ \\
\hline & S3 & 3.72 & 0.0070 & $\mathrm{H} \rightarrow \mathrm{L}+1(92 \%)$ & 3.78 & 0.0136 & $\mathrm{H}-3 \rightarrow \mathrm{L}(76 \%)$ & 3.36 & 0.0175 & $\mathrm{H}-3 \rightarrow \mathrm{L}(23 \%)$ \\
\hline & & & & & & & $\mathrm{H}-2 \rightarrow \mathrm{L}(12 \%)$ & & & $\mathrm{H}-2 \rightarrow \mathrm{L}(47 \%)$ \\
\hline & & & & & & & & & & $\mathrm{H}-1 \rightarrow \mathrm{L}(28 \%)$ \\
\hline \multirow[t]{3}{*}{ PBEO } & S1 & 3.21 & 1.8447 & $\mathrm{H} \rightarrow \mathrm{L}(97 \%)$ & 2.80 & 0.5978 & $\mathrm{H} \rightarrow \mathrm{L}(98 \%)$ & 2.83 & 0.5147 & $\mathrm{H} \rightarrow \mathrm{L}(98 \%)$ \\
\hline & S2 & 3.80 & 0.0090 & $\begin{array}{l}\mathrm{H}-1 \rightarrow \mathrm{L}(76 \%) \\
\mathrm{H} \rightarrow \mathrm{L}+1(22 \%)\end{array}$ & 3.30 & 0.0447 & $\begin{array}{l}\mathrm{H}-2 \rightarrow \mathrm{L}(42 \%) \\
\mathrm{H}-1 \rightarrow \mathrm{L}(55 \%)\end{array}$ & 3.34 & 0.0343 & $\begin{array}{l}\mathrm{H}-2 \rightarrow \mathrm{L}(47 \%), \\
\mathrm{H}-1 \rightarrow \mathrm{L}(49 \%)\end{array}$ \\
\hline & S3 & 3.91 & 0.0011 & $\begin{array}{l}\mathrm{H}-1 \rightarrow \mathrm{L}(22 \%) \\
\mathrm{H} \rightarrow \mathrm{L}+1(75 \%)\end{array}$ & 3.53 & 0.0090 & $\begin{array}{l}\mathrm{H}-3 \rightarrow \mathrm{L}(78 \%) \\
\mathrm{H}-2 \rightarrow \mathrm{L}(10 \%)\end{array}$ & 3.51 & 0.0110 & $\begin{array}{l}\mathrm{H}-3 \rightarrow \mathrm{L}(27 \%), \\
\mathrm{H}-2 \rightarrow \mathrm{L}(41 \%), \\
\mathrm{H}-1 \rightarrow \mathrm{L}(31 \%)\end{array}$ \\
\hline \multirow[t]{3}{*}{ M06-2X } & S1 & 3.58 & 2.0532 & $\mathrm{H}-1 \rightarrow \mathrm{L}+1(11 \%)$ & 3.08 & 0.5548 & $\mathrm{H} \rightarrow \mathrm{L}(91 \%)$ & 3.10 & 0.4935 & $\mathrm{H} \rightarrow \mathrm{L}(92 \%)$ \\
\hline & S2 & 4.11 & 0.0107 & $\begin{array}{l}\mathrm{H}-1 \rightarrow \mathrm{L}(50 \%) \\
\mathrm{H} \rightarrow \mathrm{L}+1(45 \%)\end{array}$ & 3.72 & 0.0946 & $\begin{array}{l}\mathrm{H}-2 \rightarrow \mathrm{L}(56 \%) \\
\mathrm{H}-1 \rightarrow \mathrm{L}(31 \%)\end{array}$ & 3.75 & 0.0764 & $\begin{array}{l}\mathrm{H}-2 \rightarrow \mathrm{L}(70 \%) \\
\mathrm{H}-1 \rightarrow \mathrm{L}(18 \%)\end{array}$ \\
\hline & S3 & 4.67 & 0.0004 & $\begin{array}{l}\mathrm{H}-3 \rightarrow \mathrm{L}(11 \%) \\
\mathrm{H} \rightarrow \mathrm{L}+2(34 \%)\end{array}$ & 4.01 & 0.0032 & $\mathrm{H}-3 \rightarrow \mathrm{L}(84 \%)$ & 4.01 & 0.0095 & $\begin{array}{l}\mathrm{H}-3 \rightarrow \mathrm{L}(63 \%), \\
\mathrm{H}-1 \rightarrow \mathrm{L}(22 \%)\end{array}$ \\
\hline CAM- & S1 & 3.59 & 2.0710 & $\mathrm{H} \rightarrow \mathrm{L}(84 \%)$ & 3.08 & 0.5766 & $\mathrm{H} \rightarrow \mathrm{L}(89 \%)$ & 3.11 & 0.5144 & $\mathrm{H} \rightarrow \mathrm{L}(91 \%)$ \\
\hline \multirow[t]{2}{*}{ B3LYP } & s2 & 4.11 & 0.0110 & $\begin{array}{l}\mathrm{H}-1 \rightarrow \mathrm{L}(49 \%) \\
\mathrm{H} \rightarrow \mathrm{L}+1(45 \%)\end{array}$ & 3.86 & 0.1066 & $\begin{array}{c}\mathrm{H}-2 \rightarrow \mathrm{L}(59 \%) \\
\mathrm{H}-1 \rightarrow \mathrm{L}(28 \%)\end{array}$ & 3.90 & 0.0908 & $\begin{array}{l}\mathrm{H}-2 \rightarrow \mathrm{L}(73 \%) \\
\mathrm{H}-1 \rightarrow \mathrm{L}(15 \%)\end{array}$ \\
\hline & S3 & 4.67 & 0.0003 & $\mathrm{H} \rightarrow \mathrm{L}+2(31 \%)$ & 4.13 & 0.0019 & $\mathrm{H}-3 \rightarrow \mathrm{L}(78 \%)$ & 4.13 & 0.0192 & $\begin{array}{l}H-3 \rightarrow L(56 \%) \\
H-1 \rightarrow L(26 \%)\end{array}$ \\
\hline \multirow[t]{3}{*}{ LC-wPBE } & S1 & 3.94 & 2.1782 & $\mathrm{H}-1 \rightarrow \mathrm{L}+1$ & 3.36 & 0.5502 & $\mathrm{H} \rightarrow \mathrm{L}(80 \%)$ & 3.39 & 0.5072 & $\mathrm{H} \rightarrow \mathrm{L}(83 \%)$ \\
\hline & & & & $\begin{array}{c}(18 \%), \mathrm{H} \rightarrow \mathrm{L} \\
(74 \%)\end{array}$ & & & & & & \\
\hline & S2 & 4.44 & 0.0123 & $\begin{array}{l}\mathrm{H}-1 \rightarrow \mathrm{L}(45 \%) \\
\mathrm{H} \rightarrow \mathrm{L}+1(43 \%)\end{array}$ & 4.40 & 0.2326 & $\begin{array}{l}\mathrm{H}-2 \rightarrow \mathrm{L}(41 \%), \\
\mathrm{H}-1 \rightarrow \mathrm{L}(29 \%)\end{array}$ & 4.44 & 0.1602 & $\begin{array}{l}H-2 \rightarrow L(65 \%), \\
H-1 \rightarrow L(11 \%)\end{array}$ \\
\hline
\end{tabular}




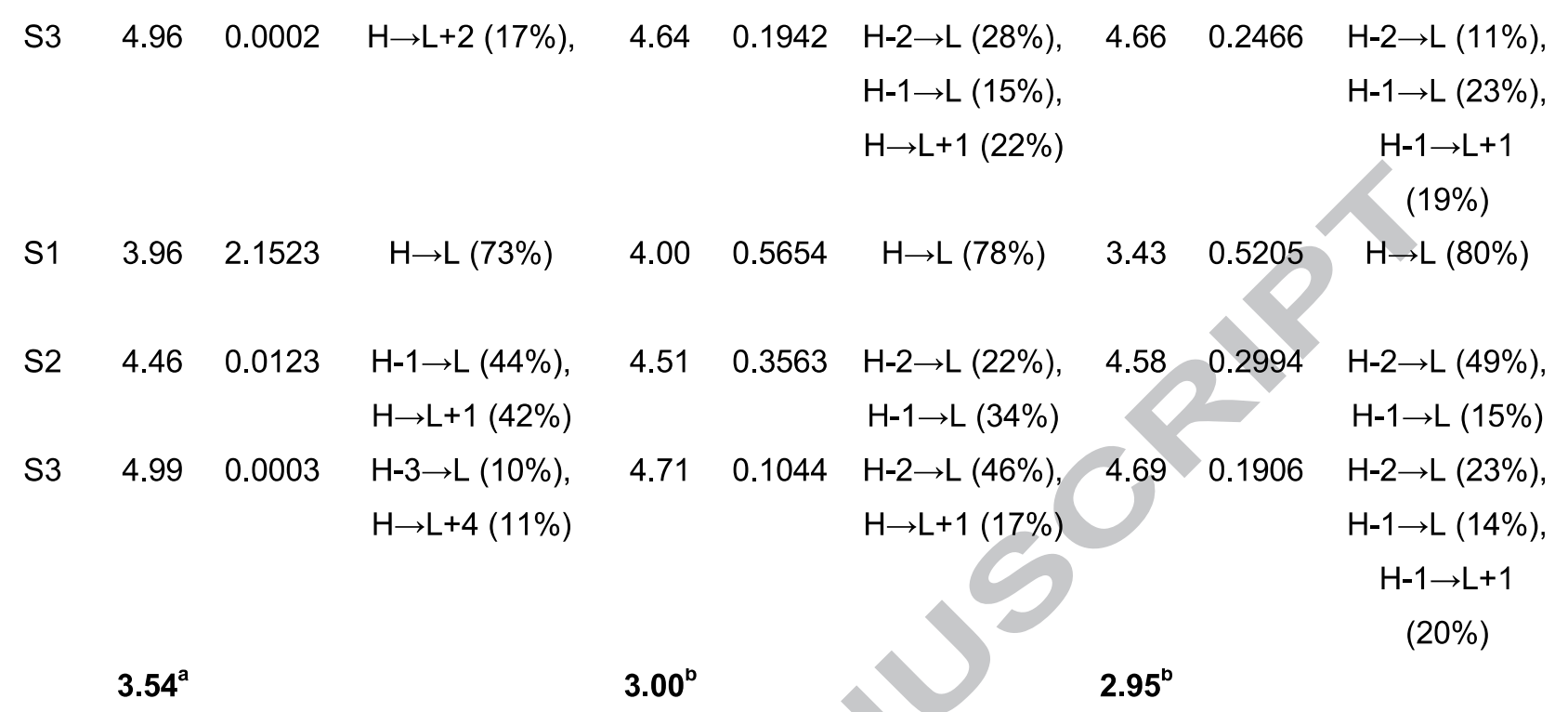

Exp
ee ref no. $25,4^{\mathrm{b}}$ See ref no. 12

Table 5. Calculated fluorescence energies $\left(S_{1} \rightarrow S_{0}\right)$, (in $e V$, Oscillator strength, $f$ ) and radiative lifetimes (in ns) of DPVBi, phospholes $\mathbf{A}$ and $\mathbf{B}$ using different functionals,

$6-31+g(d, p)$ basis set (at both LR and SS formalisms) and dichloromethane solvent.

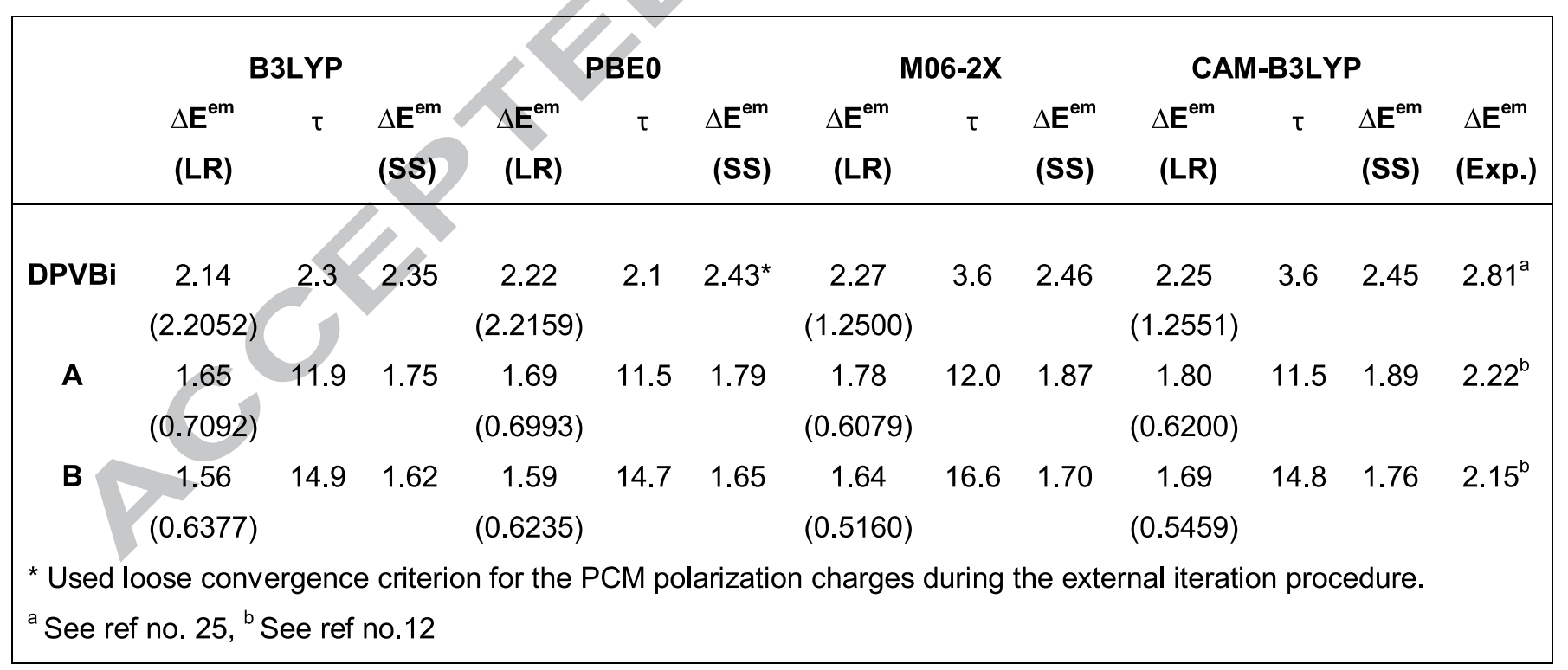




\section{Graphicalabstract}

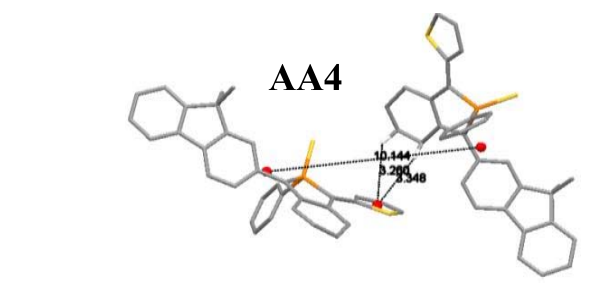

2-thienyl 5-fluorenyl thioxophosphole, A

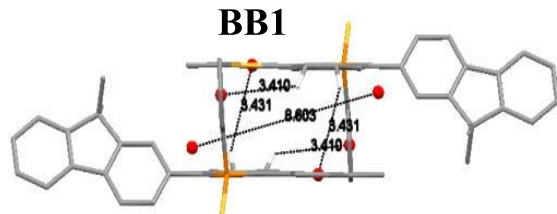

2-(5-methyl) thienyl 5-fluorenyl thioxophosphole, B

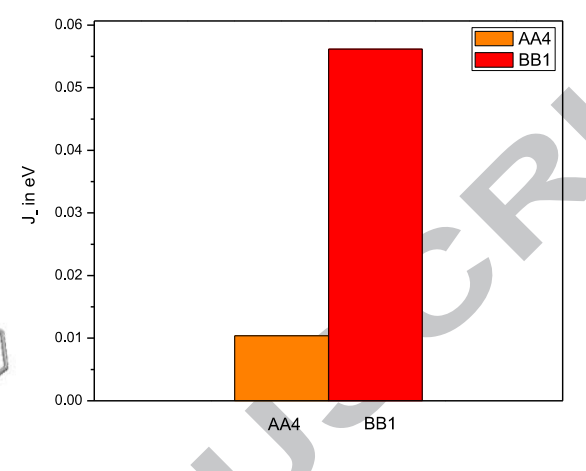

Larger transfer integrals in B due to the extra methyl group 


\section{Highlights}

Thiophene-thiophene and fluorenyl-fluorenyl interactions in phosphole B are stronger.

Larger effective charge transfer integrals $\left(J_{\text {eff }}\right)$ in phosphole $\mathbf{B}$ than phosphole $\mathbf{A}$, due to the extra methyl group.

The geometry of ES is found to be more planar than in GS. 